\title{
Personalisation, Austerity and the HR Function in the UK voluntary sector
}

\section{Abstract}

Using the customer orientated bureaucracy $(\mathrm{COB})$ construct, this qualitative study investigates changes to the Human Resource (HR) function's status in eight Scottish voluntary organisations delivering public services at a time of contradictory government calls for greater customer service (personalisation) and cost control (austerity). HR attempts to build and sustain social orders that encourage worker commitment to customer service, leading to business facing and 'business partner' strategic roles in areas of recruitment and skills. The study, however, challenges the ability of unitarist 'business partner' HR roles to resolve emerging organisational tensions concerning industrial relations, worker concerns over their own security, lack of opportunities to up-skill and service quality. It further questions whether the HR function can be strategic in this and other COB contexts as it can be powerless to resolve workplace tensions because its own status is undermined by budget cuts by government and it faces challenges to its expertise from internal and external actors such as consultants and customers.

Key words: HRM, voluntary sector, personalisation, austerity, customers.

\section{INTRODUCTION}

This study investigates changes to the role of HR managers in voluntary organisations undergoing significant reforms to employment policies as a consequence of moving towards the personalisation of social care services at a time of austerity. The personalisation of social 
services means the HR function in the voluntary social services sector faces a challenging contradictory environment. Service provision across industrialised countries is increasingly moving towards commoditised or 'cash for care' through direct payment schemes to individual service users (Ungerson and Yeandle, 2007). In the UK the most recent manifestation of 'cash for care' in social services is linked to the personalisation agenda. Personalisation seeks to improve public service quality by emphasizing the role of the service user as a customer with agency and power to direct and shape services to reflect their individual needs and aspirations, rather than 'one size fits all' provision (Needham, 2011). At the same time, calls for improved service quality coincide with significant government austerity measures and cuts in welfare expenditure following the 2008 financial crisis (Bach, 2012). Scholars have, moreover, highlighted how the two imperatives of cost and customer service represent a contradiction at the heart of public service reforms across industrialised countries (Kirkpatrick and Martinez Lucio, 1995: Kessler and Bach, 2011).

Those responsible for HR in the voluntary sector are faced with developing multiple Human Resource Management (HRM) interventions within a context of these two contradictory imperatives. To understand how this contradictory environment impacts on the HR function and management of the sector's workforce the study adopts the concept of the customerorientated bureaucracy (COB) (Korczynski, 2002). Usefully for the analytical purposes of this study, the $\mathrm{COB}$ concept identifies the dual imperatives of lower cost and customer service and quality as the fundamental tension at the heart of all contemporary service organisations and how they organise work and employment (Korczynski, 2002). The HR function is central in resolving these tensions through the construction of social orders within 
organisations from developing a mix of 'soft' and 'hard' employment policies to reflect the aforementioned dual imperatives (Korczynski, 2002: Korczynski, 2001).

In line with researcher's calls in the personalisation literature for an engaged and committed workforce (Needham, 2011), 'soft' HRM sees the workforce as a resource to be nurtured, where commitment has to be gained to fulfil organisational ends (Storey, 1992). At a time of public service austerity, 'hard' HRM policy responses will be deployed to use workers as a resource and cost like any other to be manipulated and disposed of to meet organisational requirements. Each of these approaches can exist within the same organisation (Korczynski, 2002: Storey, 1992). Moreover, another key role for HR within COBs is the containment of tensions in organisational social orders from staff resistance concerning contradictions that emerge between the dual imperatives of customer quality and cost control (Korczynski, 2002: Korczynski, 2001). At the same time, the COB is not a prescriptive construct as it leaves open how management resolves these dilemmas and tensions, and they can differ in various service settings.

This study therefore uses a theoretical framework of a multi-functional HR role within voluntary sector COBs, and addresses three research questions. The first is to understand how the contradictory environment of personalisation and austerity is changing voluntary organisation employment policies. The second, explores what tensions emerge within the workforce under personalisation and austerity. The third, investigates implications for the status and role of HR function as it grapples with multiple and contradictory demands on its expertise. 
The literature section is divided into two parts. The first presents an overview of contemporary factors shaping the status of HR in voluntary organisations delivering public services. The second outlines the potential multiple roles for the HR function in voluntary sector COBs. This is followed by an outline of the method, followed by findings and discussion and conclusion section.

\section{Personalisation, austerity and the voluntary sector}

All public services across most industrialised countries have been subject to the dual imperatives of customer orientation and rationalisation. Indeed, consumerism is seen as central to driving organisational efficiency (Korczynski, 2002). Personalisation is part of these efforts to modernise public services by, firstly, tailoring delivery to customer needs (Needham, 2011). Challenging supplier dominance, personalisation embodies choice, selfdetermination and inclusion, assuming customers can take control in their lives (Leadbeater, 2004: Poll, 2007). Subsequently, the public funding environment of the voluntary sector undergoes significant change (Needham, 2011). Block contracts or grants from local authority funders to independent voluntary sector providers diminish as resources are distributed through individual sources of funding to service users. Individualised budgets allow customers input into the planning of services to ensure tailored outcomes-focused provision; and give the ability to alter everyday routine practices and the organisational culture of providers (Rabiee, Moran and Glendenning, 2009). Moreover, they allow users the ability to choose and exit providers (Leece, 2010).

In the UK the personalisation of social care is operationalized through the provision of Direct Payments (DPs) and Individual Budgets (IBs) to users. The pressure to empower customers 
in social care in Scotland (where this study is located) through personalisation has been given statutory impetus through the introduction of the Social Care (Self-directed Support) (Scotland) Act 2012). Customer agency exists through the financial control and purchasing power given to service users through this legislation, via DPs and IBs.

Budget holders become customers shaping the employment policies and working conditions of people employed in the organisations they spend their budgets with (Baxter, Wilberforce and Glendenning, 2010). This shaping of employment policies will, however, be austerity driven. The level of resource allocated to personal budgets will represent a reduction in overall expenditure because of ongoing public service cuts in the UK (Bach, 2012). The devolved administration in Scotland has significant budgetary cuts to make up until 2020 (Scottish Government 2014). Budgetary pressure will fall on Scottish local authorities who are the main funders of the voluntary sector. The cost-efficiency aspects of personalisation in a period of severe austerity is attractive to local government service commissioners as pilots have recorded significant savings (Ellis, 2007), and it is anticipated that the value of DPs will fall as cost concerns out-weigh others (National Market Development Forum (NMDF), 2010: Ellis, 2007). Voluntary sector organisations therefore, have to attract and compete for customers within newly constructed customer-orientated social care markets that are shaped by austerity funding.

\section{The HR function in voluntary sector customer-orientated bureaucracies}

Influential typologies prescribe a path for HR functions to achieve strategic influence that include Storey’s ‘change maker' role and Ulrich's (1997) 'strategic partner'. The latter calls for HR to deliver value through achieving business priorities and meeting customer needs. 
Ulrich's typology includes other business facing roles such as 'administrative expert' charged with improving organisational efficiency and HR processes; Employee champions that maximise employee commitment and competence; and 'Change agents' that deliver cultural change (Ulrich, 1996). This was further developed into the ‘business partnership' (Ulrich and Brockbank, 2005), seen as the dominant HR model for practitioners attempting to escape marginality (Caldwell, 2003). In reality these and other roles can exist at the same time in one organisation and are undertaken by HR and other managers (Lemmergaard, 2009), and that the role of HR departments is fluid and transforms over time (Schuler, 1994).

Previous studies of HR in the voluntary sector have found that regulatory and funding priorities of external government agencies has meant, at best, variable outcomes for the function with only a few exhibiting a 'business partnership' role and a diminishing capacity to exercise the traditional employee welfare activities (Cunningham, 2010). Factors that undermine opportunities for HR in the sector mirror those in the wider economy including: poor representation on company boards; the lack of business focus; financial short-termism; the intangibility of HR's benefits; challenges from other professions to HR's expertise; the attitudes of chief executives; and relations with line managers (Kelly and Gennard, 2001: Truss, Gratton, Hope-Hailey, Stiles and Zaleska, 2002: Guthrie, Flood, Wenchuan, MacCurtain and Armstrong, et al, 2011).

The HR function in voluntary sector COBs is of potentially strategic importance, as it is responsible for helping to construct and relieve any tensions in organisational social orders as a result of contradictions between cost and customer service (Korczynski, 2002). HRM will be responsible for paring down and maximising the efficiency of lean staffing levels, without 
damaging service quality (Korczynski, 2002). While recognising that individual HR policies can operate at both 'soft' and 'hard' levels for the analytical purposes of this study, the summary of possible HRM outcomes outlined below separates them.

\section{Soft HRM interventions}

Optimistic accounts of personalisation stress a need to use 'win - win' language concerning staff and users working collaboratively co-producing services (Leadbetter, 2004: Needham and Carr, 2009). Calls to build service orientated cultures in the personalisation literature suggest changes to HR policies, including recruitment through adverts, job descriptions and person specifications being tailored to customer identity and social preferences (Carr and Dittrich, 2008). Alterations in recruitment procedures would further include attempting to build familiarity between users and employees so that selection events include the former in choosing candidates, through participation in interview panels and input into final hiring decisions (Carr and Dittrich, 2008).

The collaborative 'win-win' rhetoric of personalisation stretches to encourage worker commitment through promises to transform their skills (Needham, 2011). This includes building 'hybrid roles' where workers adopt tasks previously undertaken by other professions (Carr and Dittrich, 2008). These 'hybrid' roles encourage employees to take ownership and exercise discretion to account for greater intangibility in customer interactions (Leadbetter and Lownsborough, 2005). As a result, care work moves away from rigid provision, characterised by bureaucratic measurement of work outputs and the much criticised 15 
minute care visits (Glendenning, 2000), producing a win -win scenario for workers and customers (Needham, 2011).

There are synergies with the above and the COB construct as Korczynski (2002) sees how COBs attempt to 'delight' or 'enchant' customers. As a result, the workforce has to embrace customer-orientated norms. (Korczynski, 2002). To achieve this, COBs would attempt to emphasise the importance of 'the language and symbols used and its effect these have on the workforce' (Korczynski, 2002, pp. 67). Examples of COBs in health further identifies how public service organisations alter value-added approaches to core practices beginning with recruitment and selection and the mutual organisational, employee and customer benefits from training (Korczynski, 2002).

Combined, both sources of literature suggest a route to a strategic role for HR in voluntary organisations. The first is through involving HR as change agent (Ulrich, 1996) constructing mission statements that use the language and symbols of shared interests to promote a service orientated culture among the workforce. Consistency in service and efforts to prevent anonymity in front-line provision are focused on reducing the possibility of customers being passed from one stage of service to another among multiple workers on an assembly line (Korczynski, 2002). In altering recruitment and selection HR will, therefore, contribute again through a change agent role to help build 'pseudo-relationships' where familiarity is simulated between customers and front-line workers (Gutek, 1995). Further strategic interventions of this nature would be through improving human capital via training and 
development and altering appraisal systems to reflect customer needs (Ulrich and Brockback, 2005).

\section{Hard HRM interventions}

'Hard' HRM policy interventions would stem from several sources. Voluntary sector COBs would have to respond to customers of personalised social care services seeking value for money in an era of budget cuts by public sector funding bodies. HR will make savings in labour costs in the name of the customer, that in reality reflect externally imposed austerity cuts. This type of HR involvement implies a strategic 'business partner' role in programmes of organisational restructuring to ensure costs are controlled (Keegan and Francis, 2010).

Personalisation implies customers can express choice and the power to exit if dissatisfied by services (Needham, 2011: Rabiee, Moran and Glendenning, 2009). Again, to meet the challenge of such intangibility and uncertainty in customer demands this implies some role akin to a HR strategic business partner within a $\mathrm{COB}$, or 'administrative expert' changing hiring processes to meet demand for more part-time, temporary and other forms of flexible labour.

Additional 'hard' HRM policy changes can come in response to demands from customers for reliability and consistency in services. This can include alterations to pre-designed managerially imposed procedures and rules such as, discipline, absence and performance management to take greater account for customer sovereignty. COBs attempt to build the 
notion of 'dual authority' over employees that involves emphasizing the priorities and values of customer sovereignty, in tandem with traditional managerial forms of control (Korczynski, 2002). HR's administrative expert role can be charged with re-engineering existing organisational policies and processes to take greater cognisance of customer needs and authority.

\section{Managing tensions in the social order}

The COB is not a normative construct as it recognises tensions and conflict within the workplace that can obstruct the above management designs and this reality has implications for the role of HR (Korczynski, 2001: 2002). In the context of this study, austerity and personalisation can have negative implications for pay and conditions on provider organisations including being forced to reduce terms and conditions of employment of existing workers as well as recruiting lower paid staff with limited skills (Rummery, 2006: Dunning, 2010). Such developments imply problems with industrial relations, and/or turnover and recruitment. The introduction of a dual basis of organisational authority over staff from managers and customers may lead to tensions (Belanger and Edwards, 2013) through increasing numbers of grievance, discipline and performance management issues. Furthermore, there is little knowledge about how staff traditionally recruited because of their altruism and community service ideals in the voluntary sector (Baines, 2004) react to the commodification of care through individual budgets. In addition, workers who have been hired and socialised because of their strong empathetic relations and enjoy 'experiencing the satisfactions of assisting others' (Korczynski 2002, pp. 77) can become disillusioned when rationalisation and cost cutting undermine service quality (Baines, 2004). The personalisation literature includes sceptical views regarding the employee role and the possibility of 
subversive behaviour from professionals seeking to protect established ways of working (Ellis, 2007).

Questions therefore arise concerning what is the most appropriate role for the HR function to adopt in containing the above tensions so services are maintained in the context of cuts and rationalisation. Ulrich's typology and the advocacy of a 'business partnership' role is criticised for being unitarist portraying HRM as solely a business issue concerned with competitive priorities and targets, while employees are a resource to be utilized to achieve these objectives (Keegan and Francis, 2010).

The tensions from personalisation and austerity suggest the need to construct HR roles that are pluralist seeking to balance competing workplace interests and the views of other stakeholders (Keegan and Francis, 2010). In Canada for instance, the emergence of customers as an interest group in social services in possession of individual budgets, has led to management incorporating their involvement into managerial roles, and also formerly recognising and negotiating their rights into collective agreements (Hickey, 2012). Yet, any increased influence of customer sovereignty on collective bargaining and traditional management control systems, will probably see employees and unions seeking recognition and protection of their rights. When operating in the context of personalisation HR is, therefore, not faced with win-win-win scenarios, but a plurality of divergent interests and groups requiring the skills perhaps associated with the 'Regulator' role (Storey, 1992), including negotiation, ensuring fairness and procedural integrity in HR policies and building compromise. 
In this context, the article has address three research questions. The first is to understand how the contradictory environment of personalisation and austerity is changing voluntary organisation employment policies. The second, explores what tensions emerge within the workforce under personalisation and austerity. The third, investigates implications for the status and role of HR function as it grapples with multiple and contradictory demands on its expertise.

\section{METHOD}

The study involved in-depth, qualitative case studies in eight Scottish voluntary sector organisations (illustrated in Table 1), and semi-structured interviews with senior/line managers, employees and their representatives (81 interviews). Interviews were held with the senior manager responsible for HR in each organisation.

\section{Table 1 here}

Organisations were chosen because of their participation in developing programmes of personalisation and the introduction of new forms of individual funding. Organisations operated within local authority areas where service commissioners had participated in pilot personalisation programmes during $2011-2012$. The study focused on a diversity of providers in relation to types of service provision, i.e. learning disabilities, mental health or multiple providers. Worker respondents on the frontline were selected on the basis of their presence within pilot initiatives of personalisation. On average the proportion of women employed among participants ranged from $75-80$ percent. The profile of front-line workers interviews reflected this gender profile. The majority of female participants were returners to the labour market, in the majority aged thirty plus. 
Management respondents were asked questions relating to the impact of personalisation and austerity on the organisation's services, and the impact on HR policies and the organisation of work. Each respondent was asked questions about the significance of HR's role in programmes of change, and areas of tension. Employees were asked questions regarding their awareness of change, and the implications of austerity and personalisation on working time, skills, training, income, effort levels, service quality implications and areas of tension in employment. Interviews lasted between forty-five minutes to an hour, and were transcribed verbatim and analysed by hand. Thematic analysis was adopted through the researcher systematically moving back and forward across the dataset identifying patterns related to research questions. Sub-themes were then identified within the broader themes, and codes were generated (Miles and Huberman, 1994).

The findings are organised around three themes. The first outlines the blend of 'hard' and 'soft' HR interventions introduced by providers. The second explores the tensions in the social orders of organisations undertaking reforms associated with personalisation at a time of austerity. Throughout the analysis of these first two themes the data will reveal implications for the roles of HR specialists.

\section{FINDINGS}

Tables $2 \mathrm{a}$ and $2 \mathrm{~b}$ respectively provide an outline of the combination of 'soft' and 'hard' interventions undertaken by the eight participating organisations.

\section{Tables $2 a$ and $2 b$ here}




\section{HR interventions in voluntary sector COBs}

\section{Soft HRM policies}

There were efforts to build customer-orientated cultures among respondents through 'softer' HRM approaches. Column 2 of Table 2a shows VO 3, VO 6 and VO 7 reformulated organisational missions to reflect the values of personalisation. Even where written organisational missions remained unchanged, all respondents communicated the ideas and values of personalisation through team meetings, electronic media and other direct involvement techniques. All organisations (Column 3, Table 2a) were making changes to recruitment and selection policies so that job descriptions, person specifications and job adverts reflected the personal needs and aspirations of customers. Induction events were similarly used as devices to reinforce customer-orientated values.

Changes to recruitment suggested organisations were building 'pseudo relationships' between workers and customers in order for the latter to feel involved in who provided care for them, and that workers reflected and shared their needs and aspirations. This meant customers could have some choice over appointments. Common approaches included service visits by potential employees to interact with customers (six cases except VO 5 and VO 8); and direct customer involvement in selection panels (except VO 2 and VO 8). HR in VO3, VO 5 and VO 7 used this tailored approach to recruit staff into small, self-managing teams where each member shared the same interests and social preferences of the individual customer they served. 
Column 4 of Table 2a, illustrates that to avoid disruptions to service from absence and holidays, VO 3, VO 4, VO 5, VO 6 and VO 8 were attempting to build customer-orientated norms and construct 'pseudo relationships' among peripheral workers. Relief staff, for example, were drawn from cohorts of familiar social work students gaining experience in care work, where, again, their interests and past-times were aligned closely to those of customers to ensure that even in cases of absences and holidays there was continuity in service, skills and orientation.

Columns 5 and 6 of Table 2a illustrate organisations making efforts to socialise workers through improving human capital and developing newly empowered customer-orientated roles. VO 4 introduced direct customer involvement in the design and delivery of part of its training, and reported positive feedback from staff. From Column 6 management in VO 5 reported developmental benefits for staff from new forms of team working, where small groups of workers recruited specifically to serve one client, engaged in some selfmanagement of rotas, allocation tasks and participated with customers in designing services. VO 3 piloted a job role designed to coach customers into recovery that anticipated up-skilling and the development of new career paths through, again, building specially recruited dedicated teams working closely with customers in designing services.

Certainly from my own experience as a support worker, I've sometimes felt restricted, by what you were allowed to do within the scope of that support. I think that VO 3 staff are ready to be more creative and flexible. Having a little more liberation would be positive (SW, female, VO 3). 
A frontline manager in VO 4 reported how up-skilling and greater autonomy for staff stemmed from the new one-to-one relationships with customers.

There is more variety now in the job. It's not just working in the one house for hours, taking turns to go wherever, do whatever. There is more socialising aspect that the services do. There is more out in the community two days are never the same. I get a lot out of it (SW, female, VO 4).

To accompany changes in skills development, management in several providers (VO 5 and VO 4) were in the early stages of introducing customer involvement in appraisal (Column 7 , Table 2a) to make workers accountable for the successful achievement of outcomes that reflected the move towards independent living for service users, with VO 1, VO 6 and VO 8 actively considering similar measures.

HR's contribution to the above changes was mixed. Personalisation involved HR in strategic roles developing human capital through the aforementioned changes to training and skills. Change maker roles were apparent through the redesign of redeployment, recruitment, induction and appraisal policies and processes.

HR faced familiar problems of recognition and status through competition from other management functions, however. CEOs and senior operational managers were responsible for devising and communicating new mission statements that embraced the rhetoric of customer care. HR specialists faced competition from external actors. VO 6 and VO 7's programmes to devise communication events regarding the values of personalisation and its implications for 
work and employment were undertaken by external, specialist consultants. In this context, HR was left struggling in attempting to secure its role as employee champion to ensure all workers engaged with personalisation, as it had no input into how its values were constructed or communicated.

In relation to training, there were further mixed outcomes for HR. Greater customer involvement in training delivery in VO 4 represented a challenge to HR's status and professional standing as provider of such programmes. In other organisations, (VO3, VO2 and VO5) HR's regulator role was needed to ensure that mandatory regulations governing worker training through national vocational qualifications were met. Customers, however, were increasingly questioning the relevance of these requirements, preferring to pay for alternative training that they saw as more focused on their needs. It was HR's role in this context to sustain organisational obligations under national vocational standards, but respondents reported growing conflicts and uncertainty regarding the balance between customer rights and organisational obligations.

These kinds of things are very much going to come into play, and how do you handle regulations which is generalised and services which are individualised? There's a massive conflict there (HR respondent VO, 4).

\section{Hard HR interventions}

'Hard' HR interventions were used to introduce the values of customer service, and emphasise the disposability of employees in the face of the former's power of exit. The ability of customers to take their DPs to alternative providers was seen by senior management as a legitimate tool to enforce greater workforce discipline and attitudinal change. 
We encourage people to think about the person using the services that's having the same authority and power as a buying customer... who could direct you, and push and pull you around and tell you what they wanted, not what you thought they wanted. Who could then turn at the end of the day and take the purchasing power and walk away saying 'cheerio, you aren’t doing what I want you to do'. You have to work hard to keep customers loyal and you have to work hard to find new customers (CEO, VO 4).

Column 2 of Table $2 \mathrm{~b}$ reveals each organisation further reported a diminished capacity to redeploy staff if customers exited as job roles were now more tailored to individual needs.

Issues around the management of attendance and absence (Column 3, Table 2b) included respondents in $\mathrm{VO} 1, \mathrm{VO} 2, \mathrm{VO} 3, \mathrm{VO} 4$ and $\mathrm{VO} 8$ indicating growing problems in accommodating worker sickness absences of more than two weeks, without incurring disquiet from users concerned with consistency of service.

So somebody's off long-term sick, or even off for a day. But this clashes with some of the aspirational elements of personalisation in terms of a person has to be fitted very tightly to what the needs of the service user are. It's not just about hours, it's the actual personality, and the interests of the worker...it's going to be a struggle to ensure that the workers that are working with any individual are consistent (HR Manager, VO 1). 
To accommodate the variety of customer choices regarding when services were delivered Table 2b (Columns 4 and 5) shows organisational demands for more flexibility in working time. Organisations altered working time through the widespread introduction of split shift systems and the use zero hour contracts (ZHCs). These ZHCs are characterised as when an employer offers employment but does not guarantee a minimum number of hours to the worker. They are an increasing phenomenon in the UK and are becoming particularly prevalent in the care sector (Adams and Deakin, 2014). Indeed, HR Managers reported how changes to working time were moving the sector towards 'Just in Time' care (CEO, VO 3). Here workers would face permanent insecurity in working hours in order to meet the intangibility of customer service.

Gone are the days of Monday to Friday, nine to five. Somebody wants to go to a nightclub that finishes at two o-clock in the morning, staff have to recognise that it's not just a job now it's somebody's life (HR Manager, (VO 6).

Another part of the 'hard' HRM agenda related to how organisations dealt with local authority budget cuts. All organisations (Columns 6 - 7) reported some change to working conditions. Column 7 reveals all organisations having to make rationalisation and savings from employment. VO 1, for example, cut pay and conditions when its only funder enforced a new hourly rate for DPs, leading to an across the board pay reduction of five percent, an extension of the working week, reduced sickness entitlement and removal of two days holiday. Again, in VO 1 twenty workers were re-interviewed for (fewer) posts at a lower paid support assistant (SA) level. VO 2, VO 4, VO 7 and VO 8 were uncertain as to the future sustainability of their terms and conditions as DPs became more common and local authorities used them as cost saving measures. 
I am not sure how much of an impact the individual budgets are going to have on the terms and conditions we have now... I can see the possibility of fragmentation of pay, but I don't know if that's going to become a reality (HR Manager, VO 2).

VO 5 and VO2 had cut line management roles while increasing the spans of control of survivors. Split shifts also did not solely reflect emerging expressions of choice among customers, but service reviews by local authorities and subsequent cuts in provision and employer efforts to resource reduced and fragmented care packages. These cuts were an additional motivation in $\mathrm{VO} 1, \mathrm{VO} 2$ and $\mathrm{VO} 7$ to recruit increasing numbers of workers on ZHCs. This was because new framework agreements from local authorities in some cases only guaranteed the organisations 300 hours of service provision annually (compared to up to 3,000 hours in an old block contract), while any remaining requests for service would be on a casual, just-in-time basis. In such circumstances workers could not be offered any security in hours or income.

Again, the impact of the above agenda had mixed implications for HR's role. It can be argued that in terms of HR's response to government cuts, and recruitment of a more flexible workforce, the function was undertaking something akin to a business-partner role that involved cutting costs and ensuring the appropriate deployment of labour to meet increased intangibility in customer (local authority and service users) demand.

However, there was evidence in several organisations that the reality for HR's role was that it was as vulnerable to cuts, suggesting a relatively low status among management. Training and skills under austerity were valued less along with HR's role as deliverer of development 
opportunities. Two organisations VO 1 and VO 2 made redundancies in their training functions. VO 1's HR and training function was slimmed down to one CIPD qualified manager who was additionally responsible for a wide range of other administrative functions. VO 2 lost half (4 posts) of a previously well-staffed learning and development function. From 2011, VO 4 was only able to fund a part-time head of HR, after making the full-time incumbent redundant. Respondents in $\mathrm{VO} 2, \mathrm{VO} 4$ and $\mathrm{VO} 5$ further doubted their capacity to build the necessary skills among their workforces, as block grants had contained funding for training but resources allocated through individual forms of funding were more uncertain.

At the same time, more interventionist HR roles were apparent. In response to emerging pressures to reduce sickness absence to ensure consistency of service, HR in VO 1 and VO 2 undertook a more traditional 'regulatory' role. This involved reminding, advising and persuading front-line operational management of the organisation's responsibilities to ensure employee rights under UK health, disability and incapability regulations. This was to ensure that individuals were not rushed back into work when sick or unfairly treated. Similar, roles to ensure procedural fairness were apparent in dealing with increasingly restricted redeployment opportunities.

\section{Tensions in the social order of organisations}

Each organisation reported one or more potential tensions in their social orders as a consequence of the above challenging environment. Moreover, in many cases, the fragile status of HR or the fact that problems were a result of externally driven factors, made it difficult for the function to resolve these tensions. 
In each organisation several front line employees expressed philosophical objections and reservations regarding personalisation and 'cash for care'.

I don't want to look at someone as a customer. I want to look at them as the individuals they are that need some help and support to get them through a period to where they recover and I don't think 'customers' and 'money'. It's the one thing that's actually making me think of changing my career. I am not here to talk to people about money... I was saying to a friend 'oh this just isn't for me'. I would love to see it going well but when you talk about money in care then it doesn't work (SW, VO 1, female).

The reality of other managers and external consultants having responsibility for disseminating the values and rhetoric of personalisation made it difficult for HR to challenge and resolve these attitudes.

Unsurprisingly, austerity measures were causing increasing strains among the workforce. Management, union representatives and employees across the cases felt that, although there were variations in vulnerability to pay cuts, in general the sector had 'gone as low as it can go' (HR Manager, VO6) before morale across the workforce would begin to suffer. This meant the application of 'hard' business facing roles did not sit easily in value driven organisations.

In VO 8, the HR respondent was compelled by the governing board to make three rounds of cuts to terms and conditions between 2011 and 2013. This was at a time when the organisation was recruiting people from business onto its governing board. When cuts were 
made to terms and conditions, employee relations became so polarised that some members of the board were lobbying to de-recognise the union. Morale was low and employee discontent was reportedly widespread as the organisation was seen as too ready to cut their conditions and the union was seen as unable to make any difference. The result was that the HR manager who had sixteen years of service resigned his post as he did not want to be associated with union de-recognition and further restructuring that brought in lower skilled staff on wages barely above National Minimum Wage and on ZHCs.

In contrast, there was some evidence that a more pluralist 'regulator' approach by HR could relieve tensions. In VO 1, initial efforts by the union to bring industrial action against the organisation subsided as the HR respondent with senior management and board approval and participation undertook joint campaigns with the union as social movement groups against local government cuts. As a result, although the cuts went ahead, the workforce recognised management and union difficulties and interviews revealed little hostility to either and continuation of strong ethos towards services.

Tensions were further emerging among workers regarding the implications of greater flexibility in their work-life balance, with split shifts a particular source of concern.

Sometimes you do struggle with work/life balance...it's more bitty. You'll maybe be there for three hours, you travel to somebody else's, and you do their afternoon support. It can be really hard trying to have a life and that is why one of the times if it's overtime, if I say no, I mean no because at some point you have to draw the line and say 'no, I've got a life' (SW, VO 5, female). 
In these circumstances, HR had to act in a traditional advisory role to line managers to provide support and assistance when they faced queries from workers for time off for their own caring responsibilities or other issues.

In VO5 the HR manager was adopting a 'regulator' role to ensure fairness in the face of emerging anxieties among front-line staff regarding personal conflicts with customers and family members in relation to appraisal and performance management. Employees feared that their status or indeed job could be threatened by the arbitrary preferences and actions of customers or family members and sought assurances that protection would be maintained under traditional disciplinary procedures.

There were signs that some workers failed to benefit from the additional discretion and empowerment promised by personalisation. Here, a major restraint was local authority interpretations of personalisation, which were reportedly in many cases limited to the distribution of individual budgets, with little consideration of wider issues of customer choice. Local authority commissioners were reportedly still too focused on hours of service rather than qualitative, lifestyle outcomes. This meant workers in VO 1, VO 2, VO 5 and VO 8 reported little need for additional training in projects that were supposed to be personalised as tasks remained largely the same.

The couple of packages that have come through, there's nothing different about the support. We're calling it something different, but we're actually doing the same thing. They (local authorities) are still just looking at hours and not at the whole picture for that individual. It's like they are just ticking boxes (Team leader, VO 3). 
In such circumstances, HR's role of strategic intervention through building human capital was undermined. Furthermore, there was little it could do in terms of dealing with workers who felt the rhetoric of personalisation did not match its reality in terms of promises for enhanced skills and greater discretion.

A further area of concern was that across organisations stagnation in skills development, the diminution of training functions and uncompetitive and declining pay levels was directly impacting on HR's ability to recruit appropriate staff who would adopt the necessary customer-orientation. VO 2, for example, could no longer recruit the skilled nurses in mental health because it could not afford the appropriate public sector pay scales. Indeed, those organisations beginning to recruit $\mathrm{ZHC}$ workers reported some regional difficulties where there were alternative labour market choices.

Organisations experienced significant emerging workforce tensions concerning service quality in the face of cuts. Service reviews under personalisation that were shaped by cuts to budgets, meant customers reportedly increasingly had to make choices between receiving personal care in the home or social activities: whereas previous services delivered both. Day centres closed and opportunities to join in group activities and socialise diminished. Workers, in turn, increasingly suspected personalisation was a mask to obscure government cuts.

Personalisation in its purest form, and if it's being done for the right reasons is a great thing...but if it's done as a cost-cutting exercise and to save money, which I do believe that is what is happening right now, then its pants! (Support Worker, VO 6) 
In situations where cost cutting impinged on services, HR was again powerless to intervene as they had no real influence on the external cuts or subsequent internal operational decisions that led to service changes.

\section{Discussion and conclusion}

Using the customer orientated bureaucracy, this study has been concerned with understanding what changes personalisation and austerity bring to the employment policies and the status and function of HR in the voluntary sector. In answering the question concerning how personalisation and austerity change voluntary organisation employment policies, data reveals a variable impact across employment relationships, as HR introduces 'hard' and 'soft' HRM policies. In the latter case, HR specialists introduced policies to recruit workers that exhibited an appropriate fit with customer lifestyles and would thus enthusiastically engage in service provision. In the former, austerity and personalisation combined to bring significant insecurity to the workforce through zero hour contracts and split shifts. Furthermore, these external government policies forced HR to undermine terms and conditions of employment.

In terms of the question concerning what personalisation means for the status and role of the HR function in voluntary organisation $\mathrm{COBs}$, this study reveals some positive prospects for professionals to develop a range of business facing (administrative expert) and even strategic roles (change maker) to reflect the growing importance of having a suite of HR policies that reflect customer choices and preferences, especially in the area of recruitment and to a degree skills development. 
The analysis furthermore brings practical lessons for the function. For although the COB is not prescriptive, the analysis reveals a range of policy interventions that can guide HR functionaries, whether in the private, public or voluntary sectors, when facing pressure to reorientate practices and workforce attitudes towards greater customer focus in social services. Not all of the insights may be relevant to all forms of social services (e.g. childcare), but data does suggest possible resolutions for HR practitioners to tensions between employee rights and customer preferences. For example, regarding issues such as absence and attendance, adequate selection, training, and socialisation of relief staff into customer-orientated norms may relieve some of the conflicts and tensions regarding user demands for consistency in service: so avoiding pressure to return people to work too early from spells of sickness. This latter point is important as the increasing power of customer choice in public service is not absolute, workers retain the power of exit or to choose alternatives if their rights are restrained.

In answering the question regarding what tensions emerge within the workplace under personalisation and austerity, findings bring further lessons for HR's role. Workplace tensions include employee concerns over the commercialisation of care; industrial relations issues; the lack of skills enhancement and fears for service quality. These findings suggest a need for HR to balance a set of competing interests in difficult circumstances rather than assume a unitarist 'win-win-win' scenario for organisations, workers and customers in personalised care systems. In such circumstances, a simple business facing strategic HR profile appears inadequate in resolving such problems. Instead, as with other scholars, (Keegan and Francis, 2010) this study confirms the continuing relevance of traditional pluralist areas of HR activity in resolving these tensions. 
Moreover, the study identifies the influence of factors (such as the state, emerging contradictions from increased customer influence and the role of external consultants) that hinder HR's efforts to escape marginality. In identifying these factors, the study has wider theoretical relevance for the COB construct in terms of explaining why HRM can fail to build and sustain worker commitment in the face of contradictory management programmes of rationalisation and customer sovereignty. Caution has to be applied to the results as this study includes only a small number of organisations, which was undertaken at the beginning of programmes of organisational change. Further studies should perhaps track longitudinal change in HR, management, workforce and client response over time.

\section{Conclusion}

This study adds to our understanding of the role of voluntary sector HR functionaries in the particular context of personalisation and austerity. Under regimes that continue the marketization of human services during austerity, prospects for an inclusive role for HRM to build 'win - win', pluralistic forms of work organisation that reconcile or ameliorate the competing interests of various actors in the sector's employment relationships are tenuous. Despite a potential strategic role, HR can be powerless in preventing disruption of its goal of constructing and sustaining fragile social orders. HR's status falls victim to the tensions between the two organising imperatives of customer quality and cost control, and is further undermined by the influence of other internal and external actors (in this case the state, consultants and customers). 


\section{References}

Adams, Z, and Deakin, S (2014). Re-Regulating Zero Hours Contracts, Institute of Employment Rights, Liverpool.

Baines, D (2004). “Caring for nothing. Work organisation and unwaged labour in social services”, Work, Employment and Society, 18 (2), 267-295.

Bach, S (2012). "Shrinking the state or the Big Society? Public service employment relations in an era of austerity", Industrial Relations Journal, 43, (5), 399-415.

Belanger, J and Edwards, P (2013). The nature of front-line service work: distinctive features and continuity in the employment relationship. Work, employment and society, 27 (3), 433450.

Baxter, K Wilberforce, M and Glendenning, C (2010). Personal Budgets and the Workforce Implications for Social Care Providers: Expectations and Early Experiences. Social Policy and Society, 10 (1), 55 - 70.

Bolton, S (2002). Consumer is king in the NHS. International Journal of Public Sector Management, 15 (2), 129-39. 
Caldwell, R (2003). The Changing Roles of Personnel Managers: Old Ambiguities, New Uncertainties. Journal of Management Studies, 40 (6), 983-1004.

Carr, S and Dittrich, S (2008). Personalisation: a Rough Guide, London,

Carrol, S, (2010). SNP accused of putting 'party before nation' as Scottish draft budget is unveiled. The Guardian, 17, 10. 10.

Cunningham, I (2010). The HR function in purchaser - provider relationships: insights from the UK voluntary sector. Human Resource Management Journal, 20 (2), 189-205.

Ellis, K (2007). Direct Payments and Social Work Practice: The Significance of 'Street-Level Bureaucracy' in Determining Eligibility. British Journal of Social Work, 37, (3), 405-22.

Gutek, B (1995). The Dynamics of Service. San Francisco: Jossey-Bass.

Guthrie, J.P, Flood, P.C, Wenchuan, L, MacCurtain, S and Armstrong, C (2011). Big hat, no cattle? The relationship between use of high performance work systems and managerial perceptions of HR departments. International Journal of Human Resource Management, 22 (8), 1672-1683.

Hickey, R (2012). End-users, Public Services, and Industrial Relations: The Restructuring of Social Services in Ontario, Relations Industriellles, 67 (4), 590-611. 
Keegan, A and Francis, H (2010). Practitioner talk: the changing textscape of HRM and emergence of HR business partnership. International Journal of Human Resource Management. 21 (6), 873-898.

Kelly, J and Gennard, J (2001). Power and Influence in the Boardroom: The Role of the Personnel/HR Director. London, Routledge.

Kessler, I and Bach, S (2011). The Citizen-Consumer as Industrial Relations Actor: New Ways of Working and the End-user in Social Care. British Journal of Industrial Relations. 49 (1), 80-102.

Korczynski, M (2001). The contradictions of service work: The call centre as customerorientated bureaucracy. In Sturdy, A, Grugulis, I and Wilmott, H (eds). Customer Service: Empowerment and Entrapment. (pp. 41-62) Basingstoke, Macmillan/Palgrave.

Korczynski, M (2002). Human Resource Management in Service Work. Basingstoke: Palgrave, MacMillan.

Leadbetter, C and Lownsborough, H (2005). Personalisation and Participation: The Future of Social Care in Scotland. Edinburgh, Demos.

Leece, J (2010). Paying the piper and calling the tune: Power and the direct payment relationship. British Journal of Social Work, 40 (1), 188-206. 
Lemmergaard, J (2009). From Administrative Expert to Strategic Partner. Employee Relations. 31, (3) 182-196.

National Council for Voluntary Organisations (NCVO) (2014). Voluntary Sector Almanac. London.

National Market Development Forum (2010). National Market Development Forum Papers. London.

Needham, C (2011). Personalising Public Services: Understanding the personalisation narrative. Policy Press, University of Bristol, Bristol.

Needham, C and Carr, S (2009). Co-production: An Emerging Evidence Base for Social Care Transformation. London: London Social Care Institute for Excellence.

Poll, C (2007). Co-production in Supported Housing: KeyRing Living Support Networks and Neighbourhood Networks., in Research Highlights in Social Work: Co-production and Personalisation in Social Care, Changing Relationships in the Provision of Social Care 49, 49-66.

Rabiee, P, Moran, N and Glendinning, C (2009). Individual Budgets: Lessons from Early Users Experiences. British Journal of Social Work, 39 (5), 918-935. 
Ridder, H.G and McCandless, A (2008). Influences on the architecture of human resource management in non-profit Organisations: an analytical framework. Nonprofit and Voluntary Sector Quarterly, 20 (10), 1-18.

Schuler, R.S (1994). World Class Human Resource Departments: Six Critical Issues. Accounting and Business Review 1, 43-72.

Storey, J (1992). Developments in the Management of Human Resources. Oxford, Blackwell.

Truss, C, Grattan, L, Hope-Hailey, V, Stiles, P and Zaleska, J (2002). Paying the piper: choice and constraint in changing HR functional roles. Human Resource Management Journal 12 (2), 39-63.

Torrington, D, Hall, L and Taylor, S (2005). Human Resource Management. (6 ${ }^{\text {th }}$ ed). Upper Saddle River, NJ: Prentice Hall.

Tyson, S and Fell, A (1986). Evaluating the Personnel Function. $1^{\text {st }}$ edition, London, Hutchison.

Ulrich, D (1997). Human Resource Champions. Boston, MA, Harvard University Press.

Ulrich, D and Brockbank, W (2005). The HR Value Proposition. Cambridge, MA: Harvard Business School Press. 
Yeandle, S and Ungerson, C (2007). Conceptualizing Cash for Care: The Origins of Contemporary Debates. In Ungerson, C and Yeandle, S eds, Cash for Care in Developed Welfare States, Palgrave, Macmillan, Houndmills, pp. 1-12. 